\title{
FORMAÇÃO EM PSICOLOGIA: UMA ANÁLISE CURRICULAR DE CURSOS DE GRADUAÇÃO NO BRASIL
}

\author{
Caio RUDÁ 1 \\ Denise COUTINHO ${ }^{2}$ \\ Naomar de ALMEIDA FILHO ${ }^{3}$
}

\begin{abstract}
RESUMO
A formação em Psicologia no Brasil tem sido amplamente estudada e discutida em ambientes acadêmicos, desde antes da sua institucionalização em universidades e faculdades. Diante da escassez de estudos críticos acerca da educação superior nacional, este estudo se propõe a examinar a formação em Psicologia como consequência da constituição peculiar da educação superior no Brasil, visando à sua caracterização por meio de uma abordagem comparativa. Mediante um estudo de casos múltiplos, buscou-se analisar a formação em psicologia, no nível de graduação. Os principais resultados apontam para uma estrutura de formação anacrônica, não condizente com as especificidades ontológicas da Psicologia e apartada das expectativas acerca do papel da educação superior na formação cidadã crítica e profissional. Acredita-se, portanto, que a formação em Psicologia deve ser revista em todas as dimensões, desde seus marcos normativos aos tipos de componentes curriculares. Aponta-se uma desejável revisão da arquitetura acadêmica, substituindo o tradicional arranjo linear pelo regime de ciclos. Desse modo, toda a formação inicial estaria assentada em uma etapa propedêutica, sendo complementada numa segunda etapa que ofereceria conteúdos estruturantes do campo psicológico e habilitaria à utilização de instrumentos e técnicas psicológicos indispensáveis à atuação profissional. Por fim, uma profissionalização mais efetiva dar-se-ia num terceiro ciclo de formação especializada, conforme áreas de especialidade e atuação ou orientações teórico-metodológicas, em programas de residência e/ou mestrado ou doutorado profissional.
\end{abstract}

PALAVRAS-CHAVE: Formação em psicologia; Currículo; Educação Superior no Brasil.

\footnotetext{
${ }^{1}$ Professor Assistente do Centro de Formação em Ciências da Saúde da UFSB. Graduado em Psicologia e mestre em Estudos Interdisciplinares sobre a Universidade, ambos pela Universidade Federal da Bahia (UFBA). Foi Vicecoordenador do Núcleo Salvador da Associação Brasileira de Ensino de Psicologia (ABEP), na gestão 20152017. Dedica-se ao estudo da formação em Psicologia e do sistema de educação superior brasileiro. E-mail: caioruda.o@gmail.com

${ }^{2}$ Professora Associada do Instituto de Psicologia da UFBA. Doutora em Letras e Linguística pela UFBA, tendo realizado Doutorado-Sanduíche em Princeton University. Especialista em tradução francesa. Graduada em Psicologia pela UFBA, com formação em Psicanálise. Docente Permanente do Programa de Pós-Graduação em Artes Cênicas e colaboradora no Programa de Pós-Graduação em Psicologia da UFBA. Atualmente exerce as funções de Vice-Coordenadora e Coordenadora Acadêmica do Programa de Pós-Graduação em Artes Cênicas da UFBA. E-mail: denisecoutinho1@gmail.com

${ }^{3}$ Professor Titular de Epidemiologia do Instituto de Saúde Coletiva da Universidade Federal da Bahia UFBA. Médico, Mestre em Saúde Comunitária, Ph.D. em Epidemiologia. Doctor of Science Honoris Causa da McGill University, Canadá. Professor Visitante nas universidades: Universidade da Carolina do Norte, em Chapel Hill, Universidade da Califórnia em Berkeley, Universidade de Montreal e Universidade Harvard. E-mail: naomaralmeida@gmail.com
} 


\title{
PROFESSIONAL EDUCATION IN PSYCHOLOGY: CURRICULUM ANALYSIS OF TRAINING PROGRAMS IN BRAZIL
}

\begin{abstract}
Professional training in Psychology in Brazil has been widely studied and discussed in academic settings, long before its institutionalization in universities and faculties. Faced with the scarcity of critical studies about national higher education, this study aims to examine professional training in psychology as a consequence of the peculiar constitution of higher education in Brazil, aiming at its critical characterization with a comparative approach. Through a multiple case study, we sought to analyze the Psychology training at the undergraduate level (as it is in Brazil). The main results point to the existence of an anachronistic teaching-learning process framework, not consistent with the ontological specificities of Psychology and away from expectations about the role of tertiary education in the formation of professionals as critical and concerned citizens. It is proposed, therefore, that training in Psychology must be reviewed in all dimensions, from its normative frameworks to the types of curricular components. A necessary revision of the curricular architecture is advised, replacing the traditional linear arrangement for a cycle regimen. Thus, the initial training would be seated on a propaedeutic stage, complemented in a second stage that would provide structural contents of the psychological field and would enable the use of psychological instruments and techniques essential to the professional practice in any context. Finally, an effective professionalization would happen in a third cycle of specialized training, according to areas of expertise and practice or theoretical and methodological guidelines, in residency programs and/or in professional masters or doctorates.
\end{abstract}

KEYWORDS: Psychologist Education; Curriculum Analysis; Higher Education in Brazil.

\section{LA FORMACIÓN EN PSICOLOGÍA: ANALISIS CURRICULAR DE CARRERAS DE GRADO EN BRASIL}

\section{RESUMEN}

La formación en Psicología en Brasil ha sido ampliamente estudiada y discutida en ambientes académicos, desde antes de su institucionalización en universidades y facultades. Ante la escasez de estudios críticos acerca de la educación superior nacional, este estudio propone examinar la formación en Psicología como consecuencia de la constitución peculiar de la educación superior en Brasil, buscando su caracterización por medio de un enfoque comparativo. Mediante un estudio de casos múltiples, se buscó analizar la formación en psicología, en el nivel de grado. Los principales resultados apuntan que existe una estructura de formación anacrónica, no acorde con las especificidades ontológicas de la Psicología y apartada de las expectativas acerca del papel de la educación superior en la formación ciudadana crítica y profesional. Se cree, por lo tanto, que la formación en Psicología debe ser revisada en todas las dimensiones, desde sus marcos normativos hasta los componentes curriculares. Se apunta una deseable revisión de la arquitectura académica, sustituyendo el tradicional arreglo lineal por el régimen de ciclos. De ese modo, toda la formación inicial estaría asentada en una etapa propedéutica, siendo complementada en una segunda etapa que ofrecería contenidos estructurantes del campo psicológico y habilitaría la utilización de instrumentos y técnicas psicológicos indispensables para la actuación profesional. Por último, una profesionalización más efectiva se daría en un tercer ciclo de formación especializada, según áreas de especialidad y actuación o orientaciones teórico-metodológicas, en programas de residencia y / o maestría o doctorado profesional.

PALABRAS CLAVE: Formación de psicológos; Analisis Curricular; Enseñanza Superior en Brasil. 


\section{INTRODUÇÃO}

O debate acerca da formação em Psicologia tem acompanhado o desenvolvimento do campo no Brasil, apresentando uma marcada diversidade teórico-metodológica (COSTA et al., 2012). Das questões estritamente curriculares e pedagógicas à discussão de tópicos gerais como laicidade, atuação em políticas públicas, gênero e raça, a intensa e variada literatura indica que a formação constitui um fenômeno com muitos desafios a serem reconhecidos e enfrentados.

Estudos sobre o sistema nacional de educação superior em geral caracterizam-se por uma tendência mais descritiva e menos analítico-crítica. No particular, o mesmo ocorre com a formação em Psicologia que, apesar de bastante problematizada em ambientes acadêmicos e profissionais, também carece de modelos de análise que abordem o tema de maneira sistemática. Em particular, conforme destacam Costa e colaboradores (2012), esse campo de pesquisa apresenta-se disperso, majoritariamente com trabalhos de caráter ocasional e opinativo. Além disso, repete uma tendência da literatura sobre a formação superior em saúde, que dá ênfase a aspectos específicos, internos ou parciais do processo de ensino-aprendizagem (ROCHA, 2014).

O presente estudo se insere numa perspectiva crítica do debate sobre a formação, a partir de um referencial teórico capaz de contemplar o fenômeno em sua complexidade, considerando a conformação do atual modelo de educação superior brasileiro, pautado no treinamento profissional. Em suma, buscou-se a superação de uma abordagem internalista, incorporando à análise da formação uma perspectiva histórica e social dos processos de ensino-aprendizagem em Psicologia. Nesse sentido, o objetivo geral foi analisar a formação em Psicologia desenvolvida em cinco instituições de ensino superior (IES) no Brasil, apresentando o desenvolvimento histórico do atual modelo de educação superior, cujo exame permitiu destacar marcas identitárias e avaliar seu impacto no processo de formação.

\section{EDUCAÇÃO SUPERIOR E FORMAÇÃO EM PSICOLOGIA NO BRASIL}

Estritamente ligadas à estratégia de colonização, as primeiras iniciativas educacionais no período colonial couberam aos jesuítas, cujos colégios serviram como instrumento de 


\section{e-Curriculum}

formação da elite nacional (RIBEIRO, 2007). A partir da chegada da família real, em 1808, implantam-se cursos superiores, faculdades, escolas e academias profissionais, consolidando dois elementos que até hoje estruturam o sistema de ensino superior no Brasil: a organização autônoma não-universitária e a vocação profissionalista, herdados da tradição francesa (ALMEIDA FILHO, 2007).

As faculdades e escolas criadas a partir do século XIX constituíram-se como nicho de formação das camadas superiores da sociedade, com o intuito de prepará-las para atividades político-burocráticas e para o exercício das profissões liberais (CUNHA, 2007; TEIXEIRA, 1969). Concomitantemente à criação dessas primeiras instituições, o próprio Estado se conformava, entre ambos se estabelecendo uma relação simbiótica.

A busca pelo diploma significou a tentativa de emular a aristocracia europeia, com seus títulos nobiliárquicos e privilégios. Conforme Freyre (1977, p. 576), tendo o patriarcado rural entrado em decadência durante o século XIX, resultado de transformações políticas, econômicas e sociais que o país enfrentou na passagem do período colonial ao Império, abriuse espaço para uma nova aristocracia - a nobreza "de toga e de beca". A nação brasileira, portanto, constituiu-se pelo trabalho político dessa nova casta na edificação de uma estrutura social baseada na exclusão, formada pelo poder e prestígio adquiridos pelos poucos cidadãos (sendo as mulheres em princípio excluídas da formação profissional) que se diplomavam no ensino superior, normalmente com o grau de bacharel. Esse fenômeno foi designado por Gilberto Freyre (1977) como bacharelismo.

A peculiar educação superior brasileira, restrita desde o século XIX a escolas e faculdades profissionais, caracterizou-se predominantemente pela função de formação das elites do país. Juntas, a característica elitista e a inclinação profissionalista da educação superior vão delinear a formação da sociedade brasileira na primeira metade do século XX, separando uma minúscula elite profissional de um enorme contingente populacional alheio a qualquer espécie de escolarização, primária, secundária ou superior.

Nesse quadro, a conquista da cidadania no Brasil ocorre associada a um sistema de estratificação ocupacional. Na prática, os direitos de cidadão vincularam-se a ocupações reconhecidas e definidas em lei, situação qualificada como cidadania regulada, na qual "os direitos do cidadão restringem-se aos direitos do lugar que ocupa no processo produtivo, tal como reconhecido por lei. Tornam-se pré-cidadãos, assim, todos aqueles cuja ocupação a lei desconhece" (SANTOS, 1987, p. 68). Dessa forma, a educação superior integra um processo 
complexo de reprodução social, conforme proposto por Bourdieu (1998/1974), referindo-se às diversas estratégias empreendidas por detentores do poder político para manutenção e perpetuação de uma dada ordem social.

Atualmente, nem mesmo a evolução recente do sistema público de educação superior, com aumento do número de vagas e incipiente abertura a modelos de formação interdisciplinares e menos tecnicistas, foi capaz de fazer frente ao intenso entrelaçamento da profissionalização à garantia de direitos fundamentais. Impulsionado pela mercantilização da área educacional, prevalece hoje o mesmo referencial técnico-profissionalista (CUNHA, 2007; NUNES; CARVALHO, 2007; ALMEIDA FILHO, 2007, 2009), sendo o diploma um fim em si mesmo, aparentemente desprovido de significado para além da certificação profissional, a partir da qual se dá o acesso à cidadania e aos direitos a ela associados.

Para apreciar essa constatação, basta observar os dados do Censo da Educação Superior 2016, os quais evidenciam que os dez cursos com maior número de matrículas são todos ligados às profissões regulamentadas, totalizando $51 \%$ de todas as matrículas no sistema (INSTITUTO NACIONAL DE ESTUDOS E PESQUISAS EDUCACIONAIS ANÍSIO TEIXEIRA [INEP], 2017). Com o predomínio da função de formação profissional, esses dados evidenciam que o ensino superior tem sido pouco acessado no que respeita a uma formação generalista, sem objetivos pragmáticos.

A profissão de psicólogo, evidentemente, não dista dessa condição. Há atualmente no país um total de 293.919 psicólogos registrados (CONSELHO FEDERAL DE PSICOLOGIA, 2017), figurando juntamente com a Argentina como um dos países com maior número de psicólogos per capita em todo o mundo. Para a formação desse enorme contingente de profissionais, de acordo com o Censo da Educação Superior 2015, o Brasil contava, nesse mesmo ano, com 560 cursos de graduação em Psicologia, sendo a $14^{\circ}$ área profissional em número de cursos, nos quais estavam matriculados 223.490 estudantes, o que representa uma média de 399 matrículas por curso. A área, portanto, ficava atrás apenas do Direito e da Engenharia Civil, com médias de 728 e 474 matrículas por curso, respectivamente. Em números absolutos, o ano de 2016 totalizou 235.594 matrículas em cursos de graduação em Psicologia, sendo a $7^{\circ}$ área com maior número de estudantes ativos (INEP, 2017).

Se por um lado esses dados indicam uma consideração positiva da Psicologia por parte da sociedade, a ponto de atrair tantos interessados nos fenômenos psi, por outro, apontam que 


\section{e-Curriculum}

a categoria pode estar lidando com saturação no mundo do trabalho e, em consequência, com baixa remuneração (YAMAMOTO, FREIRE e COSTA, 2013). O descaso governamental, desde a esfera municipal à federal, implica, entre outros problemas, a manutenção de condições de trabalho inadequadas e salários baixíssimos - vide o veto presidencial ao Projeto de Lei $\mathrm{n}^{\circ}$ 3.338/08, em 2014, que previa decréscimo da jornada de trabalho da categoria para 30 horas, sem redução salarial.

A reconhecida importância da Psicologia na organização da burocracia estatal e na racionalização do processo produtivo, sobretudo a partir da década de 1930 (ANTUNES, 2006; MIRA Y LOPEZ, 1955), parece não ter sido mantida após a regulamentação da profissão, em 1962. Os cursos de graduação em Psicologia proliferaram pelo país durante a década de 1960, havendo um salto no número de estudantes que, entre 1962 e 1968, passaram de 56 a 2.000 um impressionante aumento de 3.500\% (VAN KOLCK, 1975). Durante a fase de expansão da educação superior que ocorreu entre 1970 e 1980, a Psicologia cresceu enormemente, gerando um cenário de abertura indiscriminada de cursos, com docentes despreparados, instalações inadequadas e falta de insumos necessários (ANGELINI, 1975; VAN KOLCK, 1975).

Regulamentada pela Lei no 4.119/62, a formação em Psicologia no Brasil conduzia a três habilitações distintas: licenciado, bacharel e psicólogo, sendo uma das duas últimas obrigatória para a primeira. Ao longo de mais de meio século de regulamentação, boa parte dos cursos investiu apenas na habilitação de psicólogo, pois um número reduzido de estudantes optava por uma das outras duas habilitações possíveis, as quais, na prática, experimentaram redução nos níveis de procura e, consequentemente, no volume de matrículas.

No processo de revisão do marco normativo para a formação em Psicologia no Brasil, após longo e conturbado processo de negociação, as Diretrizes Curriculares Nacionais (DCNs) para os cursos de graduação em Psicologia de 2004 terminaram por apontar a habilitação única para a formação, vindo, em 2011, sugerir, a partir de novas DCNs, a habilitação complementar de licenciatura, que deveria contar com projeto pedagógico específico para a formação do professor de Psicologia para a educação básica, no contexto de cada instituição. Na prática, as IES mantiveram-se indiferentes às DCNs de 2011, condição em parte derivada do processo de desvalorização enfrentado pelas licenciaturas, de modo geral, no país.

No momento atual, a formação em Psicologia tem sido alvo de críticas das mais diversas ordens, as quais parecem indicar que os cursos de graduação ofertam um ensino precário, com poucas garantias da qualidade necessária à atuação profissional. Nesse sentido, faz-se 
indispensável o estudo da formação em Psicologia no país, de modo a apontar e descrever tais fragilidades e assinalar alternativas que concretizem boas práticas de formação, favorecendo a composição de um modelo adequado aos desafios da contemporaneidade e da sociedade brasileira.

\section{REFERENCIAL METODOLÓGICO}

A pesquisa caracterizou-se como um estudo de casos múltiplos, tendo a análise documental como técnica principal, fundamentada em Bardin (1977). A escolha dos casos foi pautada nos resultados do Ranking Universitário Folha 2014 (RUF), desenvolvido pelo jornal Folha de São Paulo. Sua avaliação compreensiva de centenas de cursos de Psicologia e a utilização de indicadores diversificados orientaram esta opção.

Os resultados do RUF apontaram para o predomínio de IES localizadas na região Sudeste do país, com rara presença de cursos fora desse eixo regional. De modo a garantir representatividade nacional, acrescentamos ao critério de desempenho o geográfico, possibilitando a inserção de ao menos uma instituição de cada região do país. Foram selecionadas, então, as seguintes instituições, dentre as mais bem avaliadas: Universidade de São Paulo - USP (Sudeste), Universidade de Brasília - UnB (Centro-Oeste), Universidade Federal do Rio Grande do Sul - UFRGS (Sul), Universidade Federal da Bahia - UFBA (Nordeste), e Universidade Federal do Pará - UFPA (Norte).

O estudo compreendeu três etapas: pré-análise, conformando a reunião do material necessário, ou seja, estabelecimento do corpus; exploração do material, leitura superficial do material e avaliação da necessidade de incorporar ou descartar materiais; e, por fim, tratamento dos resultados, que configurou a análise propriamente dita, à luz do marco teórico.

No momento de pré-análise, estabelecemos o corpus, composto por matrizes curriculares, projetos pedagógicos de curso (PPC), ementas de componentes curriculares, guias de estudos, apontamentos relativos ao funcionamento, estrutura e aspectos normativos e legais dos cursos e programas. Na etapa de exploração do material, empreendemos a leitura do corpus, identificando elementos de análise delimitados pelo aporte teórico do modelo de formação disposto em Rocha (2014), com a sistematização e tabulação dos dados. Por fim, na fase de 
tratamento dos resultados realizamos a apreciação comparada dos componentes do modelo de análise, abaixo representado:

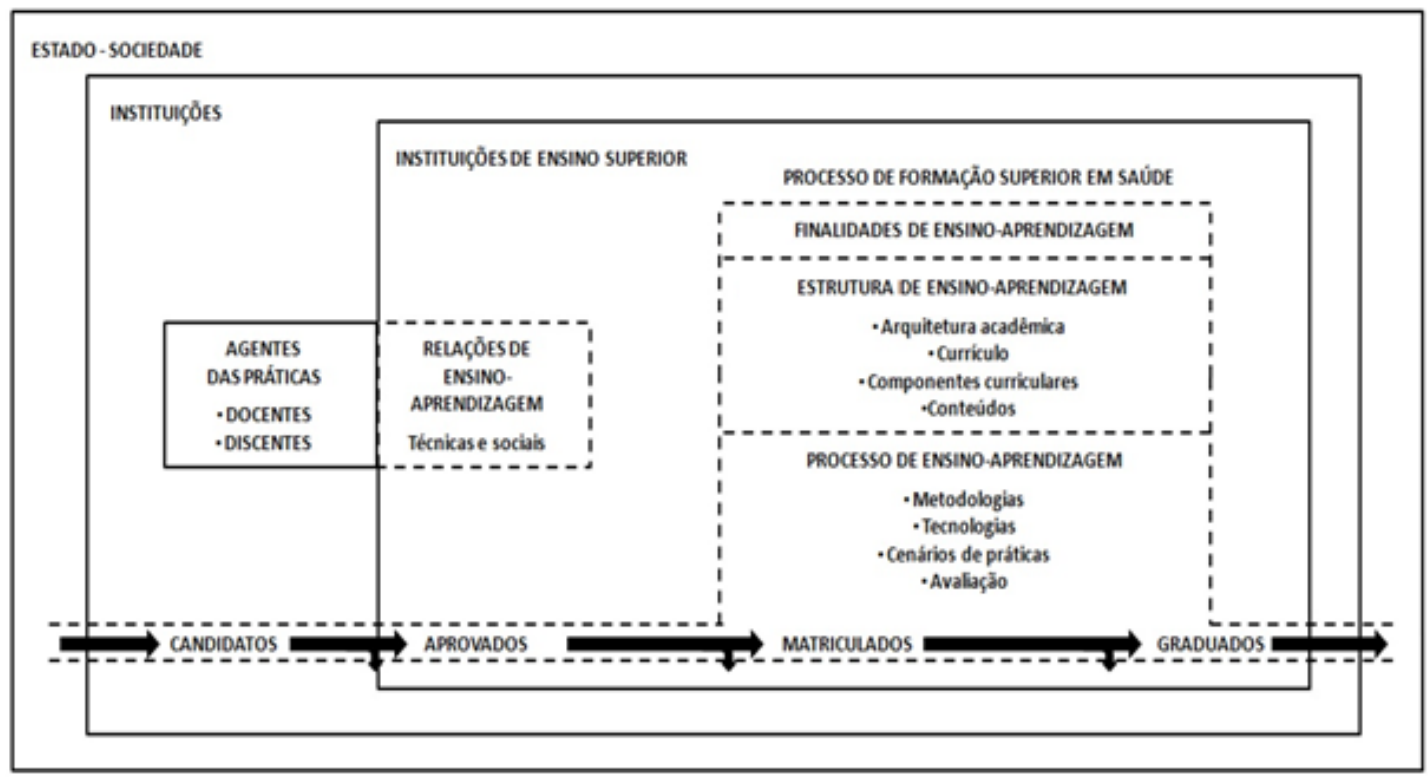

Figura 1. Modelo de formação superior em Saúde Fonte: Modelo adaptado de Rocha (2014)

Orientados pelo modelo de Rocha (2014), com pequenas adaptações, concentramos a análise na dimensão da estrutura de ensino-aprendizagem. Assim, as subdimensões estudadas foram arquitetura acadêmica (AC), compreendendo o plano geral de desenvolvimento da formação, se prevista como composição linear ou em regime de ciclos; estrutura curricular (EC), correspondendo à noção de currículo no modelo original e compreendendo a decomposição em suas respectivas etapas, blocos, séries ou eixos, no caso da Psicologia podendo obedecer à recomendação prevista de núcleo comum e de ênfases ou não; componentes curriculares (CC), agrupados conforme natureza e/ou modalidade.

A estrutura curricular foi analisada com base numa matriz composta de:

a) núcleo comum, conferindo identidade nuclear para a formação por meio do desenvolvimento de competências e habilidades gerais básicas;

b) núcleo de aprofundamento profissional, podendo ser alternativo, com opção entre ênfases curriculares, ou contingente, quando fica a cargo do estudante sua composição; 
c) bloco suplementar, correspondendo a um núcleo de atividades integralizadoras, que embora não centrais à formação são consideradas importantes à ampliação do repertório intelectual, científico, artístico e cultural do estudante.

De acordo com a natureza, os CCs podem ser:

a) obrigatórios, sendo indispensáveis à integralização curricular e cujos conteúdos são fundamentais à formação;

b) obrigatórios alternativos, sendo indispensáveis à integralização curricular, cujos conteúdos são fundamentais à formação, resguardam a capacidade de escolha do estudante, a partir de uma lista pré-definida, conforme sua opção de ênfase e/ou cadeia de seletividade;

c) optativos, cujos conteúdos apresentam estreita relação com a formação, não sendo indispensáveis, havendo possibilidade de escolha diante de um elenco pré-definido;

d) livres, cujos conteúdos podem ou não guardar relação direta com a formação pretendida.

De acordo com a modalidade, os CCs podem ser classificados em:

a) disciplina, com alto grau de sistematização no tratamento dos conteúdos curriculares;

b) atividade, mais flexível e menos sistemática, expressando-se sob forma de oficinas, seminários, projetos de pesquisa, participação em laboratórios, e trabalhos de campo;

c) estágio, que abrange desenvolvimento de experiências ocupacionais em espaços profissionais como organizações, hospitais, clínicas, instituições educacionais e/ou comunitárias, entre outros, sob a tutela/supervisão de um professor e/ou profissional de campo;

d) trabalho de conclusão de curso (TCC), atividade final que envolve execução de pesquisa, desenvolvimento de produto tecnológico ou artístico, avaliada por uma banca de especialistas;

e) atividade complementar, experiências acadêmicas livremente escolhidas, com finalidade de aprofundamento teórico e/prático em algum campo, mediante aproveitamento de estudos extracurriculares. 


\section{e-Curriculum}

Por fim, temos a dimensão dos conteúdos, cuja racionalidade de classificação empregada obedece aos eixos estruturantes sugeridos nas DCNs (BRASIL, 2004). Cumpre ressaltar que tomar tais eixos estruturantes significa uma opção, entre várias possíveis, para categorização do conhecimento e sua relação com áreas afins, a saber:

a) Fundamentos epistemológicos e históricos (FEH): conhecimento das bases epistemológicas e desenvolvimento histórico da Psicologia, mediante suas matrizes de pensamento.

b) Fundamentos teórico-metodológicos (FTM): visão abrangente dos diferentes métodos e estratégias de produção do conhecimento científico em Psicologia;

c) Procedimentos para a investigação científica e prática profissional (PIP): conjunto de instrumentos e estratégias de avaliação e de intervenção psicológica;

d) Fenômenos e processos psicológicos (FPP): objetos clássicos de investigação e atuação na Psicologia, de forma a propiciar amplo conhecimento de suas características, questões conceituais e modelos explicativos construídos no campo;

e) Interfaces com campos afins (ICA): demarcação das especificidades do fenômeno psicológico, sua interação com fenômenos biológicos, humanos e sociais, mediante compreensão integral e contextualizada dos fenômenos e processos psicológicos.

A taxonomia curricular apresentada acima visa a uma unificação de distintas terminologias utilizadas em cada IES, visto que CCs de natureza não-obrigatória, por exemplo, são referidos ora como optativos, ora como eletivos.

Para interpretar os resultados gerais dessa investigação, tomamos o conceito de modelo de formação num contexto macrossocial, envolvendo regulamentações e diretrizes educacionais nacionais. A partir dessa matriz, dividimos o processo de formação em três níveis distintos: num primeiro nível, finalidades e objetivos do processo de ensino-aprendizagem; num segundo nível, a estrutura de ensino-aprendizagem que concretiza tal processo; e num terceiro nível, o processo de ensino-aprendizagem propriamente, cada um deles agindo sobre o outro, numa orientação descendente (ver Figura 2). Como proposto no plano metodológico, focalizamos nossa análise no primeiro, através de uma aproximação teórica, e, no segundo, com o estudo empírico realizado, descartando o último nível. Ao destacar o papel das finalidades, assumimos como suposto que o processo ensino-aprendizagem seria balizado pelos demais níveis. 


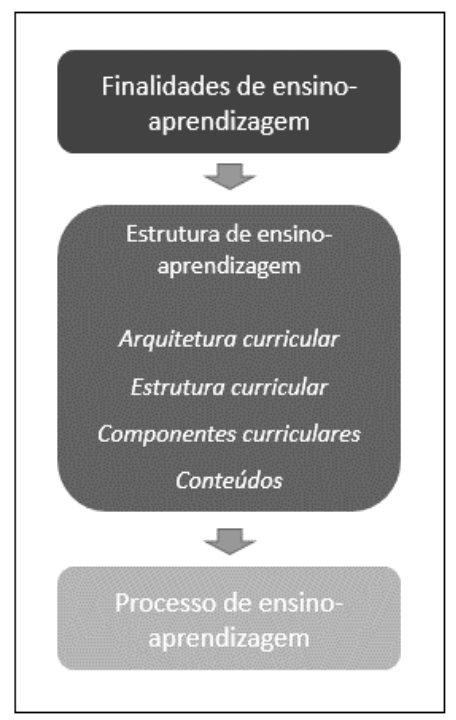

Figura 2. Representação esquemática do Processo de Formação em Psicologia Fonte: Elaboração própria

\section{RESULTADOS}

Iniciamos a apresentação dos resultados discriminando a estrutura curricular dos cursos, bem como a carga horária de cada um deles, por eixo estruturante (abaixo, na Tabela 2). Identificamos que a média da carga horária total é de aproximadamente $4.561 \mathrm{~h}$, cerca de $14 \%$ superior ao mínimo estabelecido pela legislação. A USP e a UFPA têm carga horária superior à média, esta última com um acréscimo de $35 \%$ em relação ao mínimo.

Tabela 1. Estrutura curricular dos cursos de Psicologia

\begin{tabular}{|c|c|c|c|c|c|c|c|c|c|c|}
\hline \multirow{2}{*}{ Eixo } & \multicolumn{2}{|c|}{ UFRGS } & \multicolumn{2}{|c|}{ UnB } & \multicolumn{2}{|c|}{ USP } & \multicolumn{2}{|c|}{ UFBA } & \multicolumn{2}{|c|}{ UFPA } \\
\hline & Horas & $\%$ & Horas & $\%$ & Horas & $\%$ & Horas & $\%$ & Horas & $\%$ \\
\hline Núcleo Comum & 2.130 & 51,8 & 1.800 & 42,6 & 3.710 & 76,5 & 2.924 & 69,4 & 3.900 & 72,2 \\
\hline $\begin{array}{l}\text { Núcleo de Aprof. } \\
\text { Profissional }\end{array}$ & 1.260 & 30,7 & 600 & 14,2 & 1.140 & 23,5 & 986 & 23,4 & 420 & 7,8 \\
\hline $\begin{array}{l}\text { Bloco } \\
\text { Suplementar }\end{array}$ & 720 & 17,5 & 1.830 & 43,3 & - & - & 306 & 7,3 & 1.080 & 20 \\
\hline Total & 4.110 & 100 & 4.230 & 100 & 4.850 & 100 & 4.216 & 100 & 5.400 & 100 \\
\hline
\end{tabular}




\section{$e$-Curriculum}

A carga horária média do núcleo comum é de 2.893 h, nos extremos estando a USP bastante acima, com uma percentagem elevada da carga horária total (76,5\%), e a UnB bastante abaixo, com um número bem mais reduzido (43,3\%). Essa discrepância leva, em primeira mirada, a um estranhamento, conduzindo a um questionamento sobre a racionalidade do currículo de cada IES na distribuição de componentes considerados básicos. No entanto, convém lembrar que parece não haver indicadores nacionais que estabeleçam claramente a divisão entre o que seria considerado propedêutico e o que apresentaria caráter mais profissionalizante.

A relativamente reduzida carga horária média do núcleo de aprofundamento profissional (881h) aponta para uma curiosa contradição: cursos explicitamente voltados para formação profissional apresentam carga horária ampliada no eixo propedêutico. Significa, portanto, que há concentração de CCs considerados fundamentais, possivelmente focados em discussões teóricas, em detrimento de CCs aplicados ou práticos. Subsiste, dessa forma, a despeito das orientações nas DCNs, o caráter conteudista da formação.

Sobre o núcleo profissionalizante, as DCNs sugerem a existência de ênfases curriculares - ponto que suscita polêmica -, cujas orientações são incorporadas nos cursos da UFBA, UFRGS e UFPA, ao passo que UnB e USP não as reconhecem, oferecendo ao estudante, em seu lugar, a possibilidade de um percurso acadêmico individualizado, sem conformação a um domínio específico de finalização.

Com carga horária média de $787 \mathrm{~h}$, o bloco suplementar, que pode ser tomado como indicador de abertura à interdisciplinaridade e flexibilidade curricular, apresenta grande variação entre os cursos analisados, desde aproximadamente $20 \%$, no caso da UnB, até apenas 2,4\%, no caso da UFBA que exemplifica uma formação com alto grau de fixidez e pouquíssima porosidade.

Identificamos que, a despeito de pequenas variações, a estrutura curricular permanece relativamente semelhante em todos os cursos. Quanto aos CCs, contrariamente à hipótese acerca da modelagem de instâncias inferiores pelas superiores, estas parecem variar menos em função da estrutura curricular do que de outras variáveis, não abordadas aqui. Assim, embora admita-se, por exemplo, correlação entre estrutura curricular e natureza dos CCs - quanto mais flexível a estrutura, menor a carga horária obrigatória -, uma correlação semelhante entre estrutura e modalidade de CC parece não existir. A título de ilustração, a UnB, modelo de flexibilidade curricular, é também a IES com a maior percentagem de carga horária em 
disciplinas. De modo semelhante, a UFPA, que apresenta um viés disciplinar em seus CCs também reserva um espaço razoável para atividades complementares, como as de extensão.

Tabela 2. Natureza dos componentes curriculares dos cursos de Psicologia

\begin{tabular}{lcccccccccc}
\hline & \multicolumn{2}{c}{ UFRGS } & \multicolumn{2}{c}{ UnB } & \multicolumn{2}{c}{ USP } & \multicolumn{2}{c}{ UFBA } & \multicolumn{2}{c}{ UFPA } \\
& Horas & $\%$ & Horas & $\%$ & Horas & $\%$ & Horas & $\%$ & Horas & $\%$ \\
Obrigatório & 3.030 & 73,7 & 1800 & 42,6 & 3.710 & 76,5 & 3.434 & 81,5 & 4.020 & 74,4 \\
$\begin{array}{l}\text { Obrigatório } \\
\text { alternativo }\end{array}$ & 480 & 11,7 & 600 & 14,2 & - & - & 476 & 11,3 & 480 & 8,9 \\
Optativo & 360 & 8,8 & 990 & 23,4 & 1.140 & 23,5 & 204 & 4,8 & - & - \\
Livre & 240 & 5,8 & 840 & 19,9 & - & - & 102 & 2,4 & 900 & 16,7 \\
Total & $\mathbf{4 . 1 1 0}$ & $\mathbf{1 0 0}$ & $\mathbf{4 . 2 3 0}$ & $\mathbf{1 0 0}$ & $\mathbf{4 . 8 5 0}$ & $\mathbf{1 0 0}$ & $\mathbf{4 . 2 1 6}$ & $\mathbf{1 0 0}$ & $\mathbf{5 . 4 0 0}$ & $\mathbf{1 0 0}$ \\
\hline
\end{tabular}

Fonte: Dados secundários compilados pela pesquisa

De modo geral, nos programas analisados, disciplinas constituem a modalidade de CC por excelência, havendo pouco espaço para atividades curriculares abertas e flexíveis, mesmo como atividades complementares. Nesse particular, cabe uma pequena consideração, no entanto. Embora a modalidade CC seja um indicador de flexibilidade curricular e interdisciplinaridade, na prática, uma disciplina, em função do método pedagógico utilizado pelo docente, pode apresentar abertura a campos, saberes e práticas afins, do mesmo modo que uma atividade complementar pode resguardar inclinação disciplinar. Isso possivelmente explica a ausência de CCs de modalidade atividade no currículo da UnB, um dos mais flexíveis, na medida em que disciplinas podem ser pedagogicamente conduzidas de maneira menos rígida e com aberturas.

Cumpre também tecer algumas considerações com relação ao TCC. Classicamente um símbolo da finalização da graduação, em três dos cinco cursos, não há TCC, exigido apenas pela UFRGS e UFPA. Ao buscar possíveis justificativas, encontramos no curso da UFBA quatro CCs destinados ao trabalho científico, em que os estudantes podem compensar teoricamente a ausência desse elemento na formação. No caso da USP e UnB, por sua vez, a tradição de pesquisa de ambas as instituições certamente justifica a opção pela nãoobrigatoriedade do TCC, na medida em que os estudantes, ao longo da formação, encontramse imersos num contexto acadêmico que inspira o engajamento em projetos de pesquisa, de 
modo que a aquisição de competências de investigação científica possivelmente ocorre de maneira transversal ao processo de formação, pela participação em atividades e grupos de pesquisa, bem como pela orientação empírica de muitos componentes curriculares.

Com relação aos estágios, observamos que duas instituições não cumprem o indicado pelas DCNs: mínimo de $15 \%$ de carga horária total destinada a experiências de prática profissional. Ao passo que os CCs de estágio, na UFPA e USP, contabilizam carga horária inferior ao estabelecido, a instituição gaúcha e a baiana excedem o percentual. A UFBA apresenta estrutura curricular que viabiliza experiências de contato com a realidade ocupacional desde o início, na medida em que prevê estágio básico do primeiro ao sétimo período, sendo os três últimos reservados aos estágios específicos.

Com relação às atividades complementares, com exceção da UFPA e UnB, esta modalidade de CC parece figurar meramente como exigência normativa, com pouco espaço para sua incorporação na integralização. Isto revela, além de sinalizar reduzida importância para ações de extensão e projetos extracurriculares para a formação do futuro psicólogo, fragilidade na promoção de uma formação conectada com o mundo, para além da academia.

Tabela 3. Modalidade dos componentes curriculares dos cursos de Psicologia

\begin{tabular}{lcccccccccc}
\hline & \multicolumn{2}{c}{ UFRGS } & \multicolumn{2}{c}{ UnB } & \multicolumn{2}{c}{ USP } & \multicolumn{2}{c}{ UFBA } & \multicolumn{2}{c}{ UFPA } \\
& Horas & $\%$ & Horas & $\%$ & Horas & $\%$ & Horas & $\%$ & Horas & $\%$ \\
Disciplina & 2.280 & 55,5 & 3.120 & 73,8 & 3.000 & 61,9 & 2.992 & 71 & 3.660 & 67,8 \\
Atividade & 450 & 10,9 & - & - & 1.350 & 27,8 & 204 & 4,8 & - & - \\
Estágio & 1.020 & 24,8 & 630 & 14,9 & 500 & 10,3 & 918 & 21,8 & 660 & 12,2 \\
TCC & 120 & 2,9 & - & - & - & - & - & - & 180 & 3,3 \\
Atividade & 240 & 5,8 & 480 & 11,3 & - & - & 102 & 2,4 & 900 & 16,7 \\
complementar & $\mathbf{4 . 1 1 0}$ & $\mathbf{1 0 0}$ & $\mathbf{4 . 2 3 0}$ & $\mathbf{1 0 0}$ & $\mathbf{4 . 8 5 0}$ & $\mathbf{1 0 0}$ & $\mathbf{4 . 2 1 6}$ & $\mathbf{1 0 0}$ & $\mathbf{5 . 4 0 0}$ & $\mathbf{1 0 0}$ \\
Total & & & & & & & & & &
\end{tabular}

Fonte: Dados secundários compilados pela pesquisa

No que tange a conteúdos, observamos de antemão limitações da presente investigação, impostas pela técnica de análise documental. Ao contrário dos demais elementos do processo ensino-aprendizagem, os conteúdos encontram-se mais sujeitos às contingências específicas de cada processo pedagógico, o que demandaria outra abordagem metodológica que pudesse dar conta da dinâmica da sala de aula. Por essa razão, não foi possível realizar uma análise 
aprofundada de cada CC. Além dessa limitação metodológica, destacamos uma questão que diz respeito à racionalidade epistêmica. Nesse sentido, a despeito de termos nos deparado com CCs cuja classificação claramente apontava para um dos eixos propostos pelas DCNs, outros CCs, no entanto, resistiram à imediata categorização.

Tabela 4. Conteúdos dos cursos de Psicologia por eixo epistêmico

\begin{tabular}{lcccccccccc}
\hline & \multicolumn{2}{c}{ UFRGS } & \multicolumn{2}{c}{ UnB } & \multicolumn{2}{c}{ USP } & \multicolumn{2}{c}{ UFBA } & \multicolumn{2}{c}{ UFPA } \\
& Horas & $\%$ & Horas & $\%$ & Horas & $\%$ & Horas & $\%$ & Horas & $\%$ \\
FHE & 270 & 11,4 & 180 & 10,5 & 315 & 9,2 & 408 & 16,2 & 200 & 5,6 \\
FTM & 360 & 15,2 & 870 & 50,9 & 900 & 26,3 & 714 & 28,4 & 1.220 & 34,5 \\
FPP & 540 & 22,8 & 360 & 21,1 & 1.050 & 30,7 & 544 & 21,6 & 520 & 14,7 \\
PIP & 780 & 32,9 & 210 & 12,3 & 555 & 16,2 & 544 & 21,6 & 760 & 21,5 \\
ICA & 420 & 17,7 & 420 & 17,7 & 600 & 17,5 & 306 & 12,2 & 480 & 13,6 \\
Não- & & - & - & - & - & - & - & - & 360 & 10,2 \\
discriminado & - & - & - & & & & & & & \\
Total & $\mathbf{2 . 3 7 0}$ & $\mathbf{1 0 0}$ & $\mathbf{1 . 7 1 0}$ & $\mathbf{1 0 0}$ & $\mathbf{3 . 4 2 0}$ & $\mathbf{1 0 0}$ & $\mathbf{2 . 5 1 6}$ & $\mathbf{1 0 0}$ & $\mathbf{3 . 1 8 0}$ & $\mathbf{1 0 0}$ \\
\hline
\end{tabular}

Fonte: Dados secundários compilados pela pesquisa

No que se refere a integração curricular, os resultados apontam para a existência de articulação com outras áreas do conhecimento (eixo ICA) e um enfraquecimento do eixo FHE, com menor presença e evidência em todas as IES. Já o eixo PIP apresenta variação grande entre as IES em termos de relevância para a formação. Os eixos FTM e FPP apresentam-se como mais desenvolvidos. Mais uma vez, destacamos a contradição no fato de um curso voltado para atuação profissional priorizar conteúdos teóricos em detrimento de métodos e instrumentos para atuação profissional e para a investigação científica.

\section{DISCUSSÃO}

Historicamente, o ensino superior brasileiro se constitui como espaço de formação de pessoas para atuação na burocracia estatal e nas profissões liberais. Conforme assinalado acima, o bacharelismo (Freyre, 1977) moldou a própria estrutura societal brasileira, conduzindo a uma distinção hierárquica: no topo da pirâmide, profissionais graduados, os bacharéis, e nas demais camadas, não-graduados exercendo ocupações sem exigências de qualificação, em sua maioria 


\section{e-Curriculum}

não regulamentadas pelo Estado, e sujeitos excluídos do mercado formal de trabalho, subempregados e desempregados.

Atualmente, neste país marcado por grandes desigualdades e iniquidades sociais, a posse de um diploma de graduação simbolicamente representa distinção e, concretamente, condição de acesso a melhores salários e ao acúmulo de capital cultural e econômico, embora não garanta diretamente espaço e poder na elite. Com isso, o ensino superior é, em ampla medida, profissionalmente orientado, tendo como objetivo treinamento e habilitação em certas carreiras. A estrutura curricular que realiza o processo ensino-aprendizagem consequentemente orientase pela finalidade de formação profissional. Principalmente nas universidades públicas, cursos de graduação de maior prestígio social (como Medicina, Direito, Engenharias, Arquitetura e outras, destacando-se Psicologia) tornam-se, então, espaços de treinamento para carreiras profissionais, concedendo pouco valor à formação geral cidadã.

Dessa forma, a análise da arquitetura acadêmica pertinente ao processo ensinoaprendizagem em Psicologia permite confirmar o arranjo linear, comum nas formações profissionais brasileiras, de tradição napoleônica, que remonta ao século XIX (ALMEIDA FILHO, 2007). Somente a UFBA, das cinco IES analisadas, esboça uma tentativa de implementar regime de ciclos, numa solução híbrida, com possibilidades de acesso direto a cursos de graduação em regime de progressão linear (CPL) ou via reserva de vagas para egressos do primeiro ciclo, isto é, o Bacharelado Interdisciplinar (BI). Tradicionalmente, portanto, a escolha profissional precede e determina a escolha de um curso, cujo propósito principal é dotar o egresso do conhecimento teórico e instrumentos metodológicos para o exercício de determinada profissão, evidenciando a lógica profissionalista que permeia a educação superior brasileira e valoriza o treinamento ocupacional em detrimento da formação geral (ALMEIDA FILHO, 2007).

No caso da Psicologia, essa orientação mostra-se contraditória com o esforço da categoria em se distanciar de um passado tecnicista, formando um profissional atuante na perspectiva de promoção da saúde, no combate às desigualdades sociais e na consolidação dos direitos humanos. Ao pensarmos no preparo necessário para atuar em políticas públicas, esse viés profissionalista revela-se ainda mais deletério. Tomando como exemplo a atuação do psicólogo no SUS, a tão criticada reprodução da prática clínica no contexto de saúde pública (CINTRA; BERNARDO, 2017; FERREIRA NETO, 2010) em certa medida parece derivar da falta de abertura à formação humanística e ao excessivo pragmatismo profissional. 
No que diz respeito à estrutura curricular, identificamos nos cursos analisados uma matriz tripartite, como era esperado, composta de núcleo comum, núcleo de aprofundamento profissional e bloco suplementar. Nesta análise, longe de advogarmos a diminuição da importância dos eixos FTM e FPP, e reconhecendo-os como indispensáveis para o correto manejo das técnicas profissionais, indagamos, na verdade, se a carga horária tem sido suficiente para a formação em áreas de conhecimento tão amplas, plenas de especificidades teóricometodológicas e plurais.

Em nosso entendimento, a questão repousa sobre um antigo dilema: formação básica vs formação especializada. Resgatando as questões trazidas por Benkö (1964/1965): seria o psicólogo formado como profissional ou como cientista? A resposta a esta interrogação é ponto de partida para qualquer discussão sobre a formação, o que não parece ter sido observado nas DCNs, na medida em que surge na proposta normativa um dispositivo peculiar e que tem gerado tanta polêmica: a instituição das ênfases curriculares. Dada a diversidade de contextos de inserção profissional, bem como as respectivas orientações teórico-metodológicas, as ênfases surgem como modo de compor uma pequena especialização ainda na formação graduada, embora o caráter de particularização não seja admitido pelas DCNs. Observamos, dessa maneira, que no espaço de uma graduação com carga horária mínima de 4.000h é esperada a formação de um profissional ao mesmo tempo generalista e especializado, e com vocação científica, o que nos parece uma tarefa hercúlea e dificilmente bem-sucedida, considerando as matrizes curriculares atuais. Com a implementação desse artifício curricular, reconhece-se o psicólogo como um sujeito polivalente, capacitado para pesquisa, atuação profissional e, eventualmente, para o ensino da Psicologia.

Evidentemente, estamos longe de propor uma segmentação na formação, isto é, caminhos distintos e diferenciados para o psicólogo-cientista e o psicólogo-profissional. $\mathrm{Na}$ verdade, o que chamamos psicólogo-cientista corresponde a um profissional com sólida formação básica, que apresente domínio dos referenciais teórico-metodológicos da Psicologia, clareza acerca de suas questões epistemológicas e habilidades de investigação, fundamentais tanto para o desenvolvimento de projetos de pesquisa quanto para a atuação profissional. Nesse sentido, o impasse que apontamos remete a um problema maior que diz respeito ao próprio modelo de formação. 


\section{e-Curriculum}

O âmbito da formação, por sua vez, demorou a ajustar-se às novas configurações do exercício profissional que, desde a década de 1980, vinha sofrendo profundas transformações. Sendo organizada para produzir e transmitir conhecimentos dentro de pautas conhecidas e dominadas, a instituição escolar - e podemos estender ao ensino superior, como um todo - é conservadora por natureza (BOURDIEU, 1998). Se, por um lado, a formação superior é pautada em avanços científicos e tecnológicos, por outro repete modos conservadores de reprodução social das elites. Em quatro décadas, o currículo mínimo atuou como dispositivo dessa engrenagem, tendo sido substituído por um referencial normativo que, embora apresente avanços, mantém a reprodução social, porque não resolveu o problema da excessiva inclinação profissionalista da formação superior brasileira tal como herdada da matriz franco-lusitana de ensino superior baseado em faculdades.

As DCNs possibilitaram flexibilidade curricular e, em certa medida, abriram caminho para o reconhecimento da pluralidade epistêmica da Psicologia. Porém, do ponto de vista da arquitetura acadêmica, não representaram avanço. A estrutura curricular e os conteúdos referidos a matérias específicas permaneceram praticamente inalterados. Na prática, o núcleo comum se assemelha à antiga habilitação do bacharelado e o núcleo de aprofundamento profissional à habilitação de psicólogo. Nesse modelo, a ideia de ênfase talvez indique retrocesso ao implicar uma incipiente e precoce especialização. Embora as DCNs tenham buscado a superação do paradigma disciplinar, as disciplinas permanecem como modalidade de CC mais ofertadas nos modelos de formação avaliados.

$\mathrm{Na}$ medida em que a arquitetura acadêmica permaneceu inalterada, também as finalidades da formação se mantiveram as mesmas, ainda que as DCNs tenham sido construídas com base numa retórica progressista. Verificamos, portanto, um descompasso entre as demandas sociais nas quais a Psicologia é convocada a atuar, bem como o discurso construído acerca da formação, e a estrutura de ensino-aprendizagem desta formação no nível de graduação.

Convém destacar, no entanto, em face da escolha metodológica para a seleção dos casos, que os resultados apontam para o contexto público de formação do psicólogo, que representa uma parcela mínima das matrículas: apenas 7,19\%, em 2015 (BRASIL, 2016). O presente trabalho pode indicar uma tímida presunção de representar a realidade do fenômeno estudado, sendo, ao invés, uma tentativa de fomentar uma necessária discussão. Desta forma, aponta a 
urgência de proceder análises também do setor privado, para a composição de um cenário mais abrangente do estado da formação em Psicologia no país.

\section{CONSIDERAÇÕES FINAIS}

Através de um estudo de casos múltiplos, objetivamos analisar a estrutura de ensinoaprendizagem presente na formação do psicólogo no Brasil contemporâneo. Os principais resultados apontaram para a existência de uma estrutura anacrônica, não condizente com as especificidades ontológicas do campo da Psicologia e apartada das expectativas acerca do papel das IES na formação profissional, particularmente aquelas que lidam com a interface entre a saúde e as ciências humanas e sociais.

Os resultados deste estudo indicam que, decorrido mais de meio século da regulamentação da profissão e da formação, mudou bem mais a sociedade do que a educação superior. São perceptíveis a ampliação e a diversificação do campo de trabalho, implicando novas práxis e novos desafios ocupacionais e éticos. Hoje, a Psicologia talvez seja um dos cursos de graduação com maior diversidade de possibilidades de atuação, no que diz respeito a práticas profissionais. Se antes essa atividade estava limitada à atuação clínica, escolar ou organizacional, tendendo para uma unificação de procedimentos, hoje o psicólogo atua nas mais variadas situações: em espaços comunitários, na atenção primária à saúde, na assistência social, nos contextos jurídicos, além da atuação em esporte, trânsito, ambiental, situações de catástrofe e muitos outros espaços inter ou transdisciplinares.

Consideramos, portanto, que a formação em Psicologia deve ser revista em escopo e profundidade, desde seus marcos normativos aos métodos instrucionais dos seus componentes curriculares axiais. Sinalizamos, sobretudo, para uma imprescindível revisão da arquitetura acadêmica, substituindo o tradicional arranjo linear por um regime de ciclos. Nesse sentido, a formação em Psicologia poderia assentar-se numa etapa humanizadora, formadora (no sentido da imersão na cultura) e propedêutica - como por exemplo o modelo do Bacharelado Interdisciplinar (LIMA et al., 2016a; LIMA et al., 2016b) -, sendo completada numa segunda etapa ou ciclo de formação profissionalizante. Esse momento específico ou focalizado deve oferecer conteúdos estruturantes do campo psicológico que habilite o/a estudante à utilização de instrumentos e técnicas indispensáveis à atuação profissional em variados contextos. Por 


\section{e-Curriculum}

fim, a profissionalização especializada efetiva dar-se-ia num terceiro ciclo de formação, conforme áreas de especialidade/atuação ou orientações teórico-metodológicas, em programas de residência e mestrado e doutorado profissional.

Finalmente, destacamos que o tema da formação esteve sempre marcado pelo caráter ontológico de fronteira da Psicologia - entre as Ciências Naturais, as Ciências da Saúde e as Ciências Humanas e Sociais - pelos múltiplos aportes teórico-metodológicos na abordagem científica e pelas amplas possibilidades de atuação profissional. Tal pluralidade, obliterada durante o período do currículo mínimo, não conseguiu traduzir-se em uma formação correspondente, servindo os cursos de Psicologia quase que exclusivamente à formação de profissionais técnicos cujos serviços tendiam a favorecer basicamente as elites nacionais e garantir sua reprodução social. Mudanças substantivas nesse modelo de formação poderão aproximar o campo de saberes e práticas da Psicologia às aspirações políticas e acadêmicas de fato engajadas na direção das transformações sociais de que o país tanto necessita.

\section{REFERÊNCIAS}

ALMEIDA FILHO, Naomar de. Universidade Nova: textos críticos e esperançosos. Brasília: Editora UnB; Salvador: EDUFBA, 2007.

Universidade Nova no Brasil. In: SANTOS, Boaventura de Sousa; ALMEIDA FILHO, Naomar de. A Universidade no Século XXI: para uma Universidade Nova. Coimbra: Almedina, 2009. p. 157-257.

ANGELINI, Arrigo. Aspectos atuais da profissão de psicólogo no Brasil. Boletim de Psicologia, São Paulo, v. 26, n. 69, p. 30-39, 1975.

ANTUNES, Mitsuko Aparecida Makino. A consolidação da psicologia no Brasil (19301962): sistematização de dados e algumas aproximações analíticas. Psicologia da Educação, São Paulo, n. 22, p. 79-94, 2006. Disponível em: <http://pepsic.bvsalud.org/pdf/psie/n22/v22a05.pdf>. Acesso em: 18 mar. 2014.

BARDIN, Laurence. Análise de conteúdo. Lisboa: Edições 70, 1977.

BENKÖ, Antonius. Formação profissional do psicólogo. Boletim de Psicologia, São Paulo, v. 16-17, n. 47-50, 1964-1965.

BOURDIEU, Pierre. Futuro de classe e causalidade do provável. In: NOGUEIRA, Maria Alice; CATANI, Afrânio (Orgs.). Escritos de Educação. Petrópolis: Vozes, 1998a [1974].

BOURDIEU, Pierre. Escritos em educação. Petrópolis, RJ: Vozes, 1998. 
BRASIL. Ministério da Educação. Conselho Nacional de Educação. Câmera de Ensino Superior. Parecer n⿳ 1.314. Diretrizes Curriculares para o Curso de Graduação em Psicologia, 2004a. Disponível em: 〈http://portal.mec.gov.br/cne/arquivos/pdf/ces062.pdf〉. Acesso em: 19 mar. 2014.

BRASIL. Instituto Nacional de Estudos e Pesquisa Educacionais Anísio Teixeira. Sinopse Estatística da Educação Superior 2015. Brasília: Inep, 2016. Disponível em:

<http://download.inep.gov.br/informacoes_estatisticas/sinopses_estatisticas/sinopses_educaca o_superior/sinopse_educacao_superior_2015.zip>. Acesso em 14 abr. 2019.

CINTRA, Marcela Spinardi; BERNARDO, Marcia Hespanhol. Atuação do Psicólogo na Atenção Básica do SUS e a Psicologia Social. Psicologia: Ciência e Profissão. Brasília, v. 37, n. 4, 2017. Disponível em: <http://www.scielo.br/pdf/pcp/v37n4/1414-9893-pcp-37-040883.pdf. >. Acesso em 14 abr. 2019.

CONSELHO FEDERAL DE PSICOLOGIA. A Psicologia brasileira apresentada em números. Disponível em: 〈http://www2.cfp.org.br/infografico/quantos-somos/〉. . Acesso em: 19 nov. 2017.

COSTA, Joyce Pereira et al. A produção científica sobre a formação do psicólogo no Brasil. Psicologia em Pesquisa, v. 6, n. 2, p. 130-138, 2012.

CUNHA, Luiz Antônio. A Universidade temporã: o ensino superior da colônia à era Vargas. 3. ed. São Paulo: EDUNESP, 2007.

FERREIRA NETO, João Leite. A atuação do psicólogo no SUS: análise de alguns impasses. Psicologia: Ciência e Profissão, Brasília, v. 30, n. 2, 2010. Disponível em: $<$ http://pepsic.bvsalud.org/scielo.php?script=sci_arttext\&pid=S141498932010000200013\&lng=pt\&nrm=iso >. Acesso em: 14 abr. 2019.

FIGUEIREDO, Luiz Claudio. Matrizes do pensamento psicológico. Petrópolis: Vozes, 1991.

FREYRE, Gilberto. Sobrados e mucambos: decadência do patriacardo rural e desenvolvimento urbano, 5. ed., v. 2, tomo 2. Rio de Janeiro: José Olympio, 1977.

GOMIDE, Paula Inez Cunha. A formação acadêmica: onde residem suas deficiências. In: CONSELHO FEDERAL DE PSICOLOGIA. Quem é psicólogo brasileiro? São Paulo: EDICON, 1988, p. 69-85.

INSTITUTO NACIONAL DE ESTUDOS E PESQUISAS EDUCACIONAIS ANÍSIO TEIXEIRA. Censo da Educação Superior 2016: principais resultados, 2017. Disponível em: <http://download.inep.gov.br/educacao_superior/censo_superior/documentos/2016/censo_sup erior_tabelas.pdf >. Acesso em: 20 nov. 2017. 
LIMA, Mônica; COUTINHO, Denise; ANDRADE, Jhonata; LOPEZ, Fabio Nieto.

Trajetórias acadêmicas de estudantes dos Bacharelados Interdisciplinares e do curso de Psicologia: análise de históricos escolares. Ensaio: aval.pol.públ.Educ., v. 24, n. 91, p. 395423, 2016a. Disponível em: <http://www.scielo.br/pdf/ensaio/v24n91/1809-4465-ensaio-2491-0395.pdf>. Acesso em: 11 jan. 2018.

LIMA, Mônica, COUTINHO, Denise; JALIL, Cristina Moreira; LOPEZ, Fabio Nieto. Transição dos Bacharelados Interdisciplinares para a Formação em Psicologia. Psicologia: Ciência e Profissão, v. 36, n. 1, p. 183-195, 2016b. Disponível em: <http://www.scielo.br/pdf/pcp/v36n1/1982-3703-pcp-36-1-0183.pdf>. Acesso em: 11 jan. 2018.

MIRA Y LOPEZ, Emílio. Aplicações da Psicologia no campo das atividades estatais. Arquivos Brasileiros de Psicotécnica, Rio de Janeiro, v. 7, n. 2, p. 115-126, 1955.

NUNES, Edson; CARVALHO, Márcia Marques de. Ensino universitário, corporação e profissão: paradoxos e dilemas brasileiros. Sociologias, Porto Alegre, ano 9, n. 17, p. 190215, 2009. Disponível em: 〈http://www.scielo.br/pdf/soc/n17/a08n17>. Acesso em: 18 dez. 2013.

RIBEIRO, Maria Luísa Santos. História da educação brasileira: a organização escolar. 20. ed. Campinas: Autores Associados, 2007.

ROCHA, Marcelo Nunes Dourado. Educação Superior no Brasil: tendências e perspectivas da graduação em Saúde no século XXI. 2014. 143f. Tese (Doutorado em Saúde Coletiva) Instituto de Saúde Coletiva. Universidade Federal da Bahia, Salvador, 2014.

SANTOS, Wanderley Guilherme. Cidadania e justiça: a política social na ordem brasileira. 2. ed. Rio de Janeiro: Campus, 1987.

TEIXEIRA, Anísio. O ensino superior no Brasil: análise e interpretação de sua evolução até 1969. Rio de Janeiro: Fundação Getúlio Vargas, 1969.

VAN KOLCK, Odette Lourenção. A formação e as funções do psicólogo clínico no Brasil. Boletim de Psicologia, São Paulo, v. 26, n. 69, p. 51-58, 1975.

YAMAMOTO, Oswaldo Hajime; OLIVEIRA, Isabel Fernandes; COSTA, Ana Ludmila Freire. As psicólogas e as mutações no mundo do trabalho. In: LULHIER, Louise (Org.). Quem é a psicóloga brasileira? Mulher Psicologia e Trabalho. Brasília: Conselho Federal de Psicologia, 2013, p. 114-128. 